\title{
¿Economía popular de la ciudad? Estudio de las agrupaciones familiares U6A y Nueva Generación del A. H. J. C. Mariátegui, San Juan de Lurigancho, Lima
}

Recibido: 17/10/2016

Aprobado: 28/11/2016
Alejandro Valdivieso Alvarado, Lorena Ricse Gallango, Brisaida Uceda Rafael, Víctor Chunga Alzamora,

Leonardo Diestra Quiroz ${ }^{1}$

Universidad Nacional Mayor de San Marcos

< lorenaricse.Ir@gmail.com

\section{RESUMEN}

¿Economía popular de la ciudad? El presente texto trata de responder esta pregunta mediante un análisis comparativo de las agrupaciones familiares U6A y Nueva Generación del Asentamiento Humano José Carlos Mariátegui, distrito de San Juan de Lurigancho, ciudad de Lima. Para dicho propósito se hace necesario la reconstrucción de su memoria, la visibilización de su organización y conflictos internos, de su relación con agentes externos a ellos, y por último sus perspectivas a futuro.

Palabras Clave: Economía popular, ciudad, memoria, organización, conflicto interno, futuro

\section{Popular Economy of the City? Study of the family groups U6A and Nueva Generación, J. C. Mariátegui, San Juan de Lurigancho, Lima}

ABSTRACT

Popular economy in the city? The current text tries to answer that by using a comparative analysis between two family aggrupation's; U6A and Nueva Generacion located in the human settlement Jose Carlos Mariategui, San Juan de Lurigancho distritc, Lima city. For this purpose is mandatory the reconstruction of their memory, the visibilization of their organization and intern conflicts, their relationship with extern agents and last, their future perspectives.

KEYwORDs: Popular economy, city, memory, organization, internal conflicts and future perspectives.

1 Estudiantes del $8^{\circ}$ ciclo de Sociología en la Facultad de Ciencias Sociales, UNMSM. 


\section{Introducción}

E 1 presente trabajo de investigación-acción analiza dos experiencias ubicadas en el distrito de San Juan de Lurigancho, al este de la ciudad de Lima, específicamente, estudia las asociaciones familiares (en adelante AF) U6A y Nueva Generación, situadas en las alturas del asentamiento humano José Carlos Mariátegui (en adelante JCM), integradas aproximadamente por 200 personas, donde las condiciones de vida son realmente hostiles y el riesgo es latente.

Ahí podemos encontrar varías AF que realizan diversas actividades para poder hacer frente a las adversidades que se le presentan día tras día, y que incluyen entre otras: faenas los días domingos, recolección autogestionaria de fondos, autogestión del territorio, producción social del hábitat. Las cuales podrían incluirse dentro de la noción de economía popular.

¿Qué entendemos por "economía popular"? En este caso nos referimos a Quijano que nos dice: "Lo que caracteriza la economía popular es que las relaciones de trabajo y de distribución de recursos y del producto se organizan, en lo fundamental, en torno a la reciprocidad y la vida social, las prácticas sociales cotidianas y la comunidad» (Quijano, 2011: 380).

En efecto, eso es lo que encontramos en las alturas de JCM y, en especial, en las dos AF que vamos a analizar para hacer una comparación y ver qué tanto puede variar esta economía popular en cada caso.

Estas AF no tienen como eje de la organización de la comunidad al trabajo asalariado, sino como, dicen Cabrera y Vio, los trabajos no asalariados o asalariados no contractuales, el microcrédito, el trabajo comunitario, el trabajo en el hogar, los cuales se vuelven actividades centrales de esta economía popular (Cabrera y Vio, 2014: 37-39)

Del mismo modo, Muñoz dirá que en la dimensión económica de la "ciudad popular" -o periféricaconfluye y coexisten distintas racionalidades económicas, como una racionalidad capitalista hegemónica y una racionalidad popular ligada a relaciones de reciprocidad (Muñoz, 2011: 339).

Porque en efecto son los lazos de reciprocidad los que van a organizar a las familias como comunidad para poder hacer frente a las constantes necesidades como por ejemplo: la ausencia de acceso a servicios básicos (agua, luz y desagüe), así como el saneamiento legal (título de propiedad), el acceso a la zona en sí misma (vías asfaltadas), muros de contención para prevenir deslizamientos en época de lluvias, así como escaleras de cemento para acceso peatonal, o problema con los traficantes de tierras que aprovechándose del desconocimiento de la gente vende lotes de manera ilegal (Estrada, 2015: 32).

El problema del riesgo es uno a tener en cuenta de manera especial, que merecería otra investigación; pero que se hace necesario mencionar ya que según algunos estudios especializados el riesgo en estas zonas varía según el género, la edad y las discapacidades físicas, y estaría inmerso en un círculo vicioso donde los métodos y técnicas para sobrellevarlo terminaría siendo poco efectivos. ${ }^{1}$

No podemos entender estos casos sin mencionar cómo es que Lima se ha ido expandiendo y cuál ha sido el papel del Estado. Riofrío señala que el Estado se ha encargado de dar títulos de propiedad en vez de viviendas de calidad (Riofrío, 2009). No solo eso sino que también ha habido un descuido generalizado del Estado por los asentamientos humanos y peor aún por las familias que ahora habitan las quebradas de los cerros. Así en vez de políticas que pueden dotar de vivienda a gente pobre se ha preferido apoyar a las grandes inmobiliarias y a los sectores de clase media con los créditos de programas públicos como Mi vivienda (Quispe, 2015: 29).

Sin embargo, son en estas AF que por sus condiciones de vida se organizan y salen adelante, donde tanto U6A y Nueva Generación brindan una alternativa frente al mercado formal de vivienda, al trabajo asalariado contractual (con trabajo comunal), así como una verdadera actividad en comunidad frente a la inercia de los nuevos espacios residenciales cerrados, acción frente a la inactividad por parte del Estado para incluirlos en políticas efectivas, etc. Organizaciones que llevan en promedio 20 ańos saliendo adelante, poco por poco; pero con determinación, buscando incorporarse a la ciudad o construyendo otra ciudad.

Escogimos estas dos AF porque poseen características distintas, a pesar de vivir en situaciones idénticas: U6A, más antigua y con más beneficios; pero con apoyo del gobierno del alcalde de San Juan de Lurigancho y confianza en su junta directiva, sigue teniendo prácticas de organización comunal fuertes; en comparación de Nueva Generación que, aunque es mucho más nueva, muestra desconfianza de su junta directiva, y el apoyo que recibe de la Municipalidad de San Juan

1 Ver https://www.youtube.com/watch?v=SCD3Z3dS-uI 
de Lurigancho es nulo, además que le impone trabas a todo lo que ellos quieren hacer; y evidencia lazos de solidaridad cada vez más débiles.

El presente trabajo de investigación-acción se dividirá en una reconstrucción de la memoria de ambas $\mathrm{AF}$, las relaciones que estas tejen internamente como agrupación familiar y externamente con la municipalidad, organizaciones no gubernamentales y otras AF, y sus perspectivas a futuro. Todo este proceso será enriquecido mediante la comparación de ambas experiencias y por el interés de descubrir ¿qué racionalidades guían las actividades de economía popular dentro de cada una de estas AF?

\section{Memoria: Reconstruyendo el camino de U6A y Nueva Generación}

Como hemos visto en la introducción estas son AF de las partes altas del asentamiento humano JCM, es decir, viven en las laderas de los cerros, donde durante un buen número de ańos carecieron de servicios básicos y donde comprendieron que solo de manera conjunta (solidaria y recíproca) podrían hacer frente a las adversidades que trae consigo habitar zonas como estas.

Por tal motivo, reconstruir el proceso por el cual estas AF llegaron hasta donde están se hace necesario, así se pondría en evidencia todo el proceso de "trabajo comunal" y los frutos que este tuvo y lo que aún queda por hacer.

U6A se fundó en 1995 y Nueva Generación en el 2001, exista entre ambas una diferencia de seis ańos de creación; pero pasaron y pasan, en mayor o menor medida, por las mismas dificultades y obtuvieron de forma gradual y muy parecida los diferentes servicios básicos con los que hoy cuentan.

Es así que lo expuesto por Arocena sobre la construcción de la identidad local se vuelve pertinente. Él indica que la historia y el territorio son dos elementos centrales en la construcción de la identidad local, porque es en la historia donde uno evidencia la evolución del proceso dónde se recuerdan nombres e instituciones y dónde uno evidencia que frente a las adversidades se han hecho procesos importantes. Es por eso que para Arocena: «el actor humano forma parte de una historia, pero si es realmente actor es también portador de alternativa» (Arocena, 2002: 11-12). Esta idea se complementa con la de Corragio en donde considera al territorio como «un todo complejo-natural, que incluye a la población humana y sus asentamientos como una especie particular de la vida» Coraggio, 2011: 281).

Así se podría decir que la mayoría de las AF pasaron por lo siguiente: 1) la toma de tierra en el proceso de su fundación 2) la creación de juntas directivas (presidente, delegado y tesorero) y 3) la presión para la obtención de servicios básicos y títulos de propiedad.

\section{a. La obtención de los servicios básicos}

En cuanto a los servicios básicos el primero que lograron conseguir fue la luz -hay que tener en cuenta que estos servicios también se conseguían de manera gradual dentro de cada AF- siguiendo con el agua (ambas AF la obtuvieron gracias al programa Agua para Todos que se gestó durante el gobierno del presidente Alan García) y titularidad de la tierra.

Para el caso de U6A, fundada en 1995 y teniendo como primer dirigente a Chinder Tarazona, pudo conseguir luz en la parte más baja de la agrupación familiar a mediados de 1998. La luz era un paso importante. A oscuras los riesgos eran enormes.

Así que al inicio cuando existían pocas casas que tenían luz, los de más arriba, los "Nuevos", tenía que "jalar luz del vecino"; sin embargo, se quejaban de que "cobraban lo que ellos querían, total, si no pagas no tienes luz, te lo cortan". Teodosia de U6A nos puede comentar esto:

Luz se jalaba de abajo, y eso era solo para escuchar tu radio, para un ratito. Cuando tenías el cuarto prendido te tocaban la puerta y te decían "Vecina, no te he dado luz para que estés con tu foco prendido, y pa, te cortaban". Luz llegó algo de 1998, provisional, después habíamos pagado el convenio, nos puso poste.

El agua que se obtiene en el 2009 era aún un servicio básico mucho más necesario. Los problemas que traía consigo la ausencia de este generaban muchos problemas en la salud de las personas, había muertes continuas y la gente solía atribuírselas al cerro, indicando que no se le había hecho un pago a este y él no los quería y por eso mataba a niños o a hombres tal como nos cuenta Teófila de U6A.

Mi hijita murió, después de Bertha, después de Michael su mamá, después mi hermano, después el esposo de Ely, su hija de Victoria, después la vecina del lote $10 \mathrm{y}$ seguidito murieron. 
Del mismo modo, el antiguo abastecimiento de agua lo hacían a través de los camiones cisterna de SEDAPAL; pero los "nuevos" eran los que menos acceso tenían a este, el camión se quedaba donde terminaba la vía, lugar conocido como el paradero de "La Roma", después no había vías. Las faenas estaban más concentradas en tener las primeras escaleras de piedra, debido a eso tenían que ir con baldes o en el mejor de los casos pedirle a alguien el servicio de agua mediante mangueras. Además se sigue observando el cobro excesivo por parte de algunos vecinos. La obtención de agua y luz se da durante la junta directiva dirigida por el señor Santos, quien también decidió mudarse.

U6A pasa por un largo proceso, desde 1995, la titularidad en la actualidad está completa en su mayoría; pero se le presentaban problemas en COFOPRI, ya que en algunas ocasiones la tierra sobre la que estaban viviendo tenía varios dueños (comunidad de Jicamarca, asentamiento humano JCM, Municipalidad de San Juan de Lurigancho).

El avance importante que se tiene con los procesos de titularidad se logra con la actual junta, presidida por el señor Alejandro Alarcón, quien perteneciendo a la organización "Unión de Pueblos Organizados" (UPO a partir de ahora). Ha podido, a través del apoyo que brindó a la campańa electoral del actual alcalde de San Juan de Lurigancho, conseguir fondos para poder aprobar proyectos a favor de su AF, como el actual muro de contención.

Nueva Generación pasó por un trámite similar primero luz, luego agua y aún en proceso la titulación de la tierra. José de Nueva Generación nos cuenta lo siguiente:

-E: ¿`Ya tiene luz, agua?

-Luz si tengo, aquí está mi caja, pero no tengo agua. (¿Cómo está haciendo para conseguir agua?) Los vecinos me dan, yo jalo de los vecinos de abajo, de los que sí tienen, y ellos me cobran lo que consumo (¿Cómo sabe cuánto es su consumo?) ah, porque ellos tienen medidor y de acuerdo a eso nos cobran.

La luz llega a Nueva Generación en el año 2003, primero con una caja para todas las personas que vivían en la zona más baja, y luego con medidores por lote, aquí también se hacen presentes las injusticias en cuanto al cobro por luz de algunos vecinos. Igual se agradece el apoyo recibido por parte de las personas que aún no cuentan con este servicio.
A diferencia de U6A, que padecieron buen tiempo sin agua potable, en el 2009 , gracias al proyecto Agua para todos, se abasteció de agua a cierto sector de la AF. Según su actual dirigente, Víctor Santa Cruz, son alrededor de $60 \%$ de personas las que cuentan con luz y $50 \%$ con agua potable. También en esta agrupación familiar se puede observar el mismo método de recolección de agua potable con baldes y mangueras. Por último, el proceso de titulación está en espera y es este trámite el que más desconfianza ha generado en los vecinos, tanto de la actual dirigencia como de la anterior a cargo del seńor Ambrosio, que también se mudó de la AF. El principal motivo de la desconfianza es la perdida de dinero y de la inactividad por parte de la junta directiva. Así la participación en faenas o en asambleas es cada vez menor en esta agrupación familiar.

-Si hacen reuniones, pero la verdad es que yo soy una persona práctica y no me gusta gastar saliva, porque a veces se discuten temas imposibles pues (...)pero los dirigentes siguen insistiendo, dicen que por debajo o rompiendo la mano. (José Santa Cruz)

Es en este sentido que volviendo a Arocena y a la idea de desarrollo alternativo, como es el del desarrollo local, la idea de territorio se hace potente. Las dos historias, todo por lo que pasaron ambas $\mathrm{AF}$, se dio en un lugar en específico con anclaje territorial, ya estén las personas dentro de los "antiguos" o "nuevos" hay una identificación con el territorio y una historia que compartir. Arocena señala:

El hombre se relaciona con espacios físicos bien delimitados en los que desarrolla sus actividades. Estos espacios se vuelven significativos para el grupo que los habita se cargan de sentido porque por él transitaron generaciones que fueron dejando sus huellas, las trazas de su trabajo los efectos de su acción de transformación de la naturaleza. (Arocena, 2002: 12).

La mención al desarrollo local se hace pertinente en la medida en que hay algunos supuestos básicos que comparten las alternativas de desarrollo y el desarrollo alternativo, sin embargo, es necesario dejar en claro que no compartimos la visión de comunidad cerrada que tiene el desarrollo local como diría Santos «las alternativas de producción deben de ser voraces en términos de escala» (Santos, 2011: 53). Esto nos lleva a pensar a la comunidad, propia de la economía popular, como 
una comunidad abierta propensa a tender relaciones a escalas mayores, incluso globales.

\section{Organización y conflictos internos}

\section{a. Organización social}

Tanto en U6A como en Nueva Generación existe una marcada división social legitimada por el orden de llegada a la agrupación. El orden de llegada organiza espacial y socialmente a las AF según los "Antiguos" y los "Nuevos". Siendo los "Antiguos" los primeros en asentarse, se han instalado en las partes más accesibles del cerro, por eso viven cerca uno del otro. Los "Antiguos", además, cuentan ya con saneamiento legal. Por otro lado, están los "Nuevos", quienes siendo los últimos en asentarse, se instalan en las partes más rocosas y menos accesibles del cerro. Es por eso que sus lotes se encuentran más separados uno del otro. No disponen de ningún servicio básico, es por eso que su interés gira en torno a la adquisición de estos.

Esta división social genera, diferencias en cuanto a sus intereses, perspectivas sobre el crecimiento de la agrupación, etc. Todas estas diferencias las analizaremos en mayor profundidad en el acápite dedicado a conflictos

\section{b. Organización política}

Con organización política nos referimos a los mecanismos de participación comunal, que se rigen bajo ideas de democracia directa e igualdad, estos son: Las juntas directivas y al local comunal. No abordaremos en este trabajo las implicancias del local comunal por cuestiones de espacio.

Arocena rescata el papel de los actores locales para planificar un mejor desarrollo (Arocena, 2002: 11). Este énfasis en la planificación hecha por los actores sociales corresponde a la realidad de U6A y de Nueva Generación, pues es a través de su junta y de su local que buscan incidir en su realidad. La junta se encarga de recoger las necesidades de sus representados y tiene la obligación de planificar y coordinar proyectos con diversas instituciones con el fin de subsanar estas necesidades. Lo mismo ocurre con el local comunal, pues es el espacio en donde se da el servicio del comedor. Podemos examinar, cada una por partes:

\section{- Junta directiva}

Cada Junta dispone de un presidente, un delegado, un secretario y un tesorero; cada miembro de esta junta recibe el nombre general de "dirigente" elegidos democráticamente cada año.

\section{Sobre la naturaleza de sus funciones}

Hemos podido evidenciar el papel crucial que poseen las juntas directivas para el desenvolvimiento de las AF. Identificamos dos tipos de funciones que debe tener esta organización política: Una es de corte más recíproco y popular, la otra en cambio corresponde más a un corte social reivindicativo.

Las funciones de corte popular, implican que la junta debe organizar a los habitantes en torno a las faenas. La junta debe además encargase de diseñar proyectos que puedan responder a las necesidades de la población (construcciones de pilones, muros, losas deportivas, etc.).

Por otro lado, las funciones de corte más social reivindicativo enfatizan en que la junta debe encargarse de tramitar todo lo concerniente a los títulos de propiedad y hacer el seguimiento a las respectivas instancias estatales encargadas del abastecimiento de servicios básicos.

Sin embargo, El testimonio de Alejandro, el actual presidente de U6A, nos muestra una realidad ineludible. Alejandro ante nuestra pregunta sobre los puntos de su plan de trabajo que le falta plasmar, nos comentó que:

Nosotros tenemos plan de trabajo pero desgraciadamente en la gestión, necesitamos del recurso monetario. Siempre digo a mi población, si tuviéramos dinero no estaríamos tragando tierra, estaríamos como en Las Casuarinas porque nos falta ese recurso.

De este testimonio, entendemos, que las funciones reciprocas, en tanto organización, dependen en gran medida del mercado, o del acceso al financiamiento externo por parte de diversas instituciones.

Quijano, seńala que la economía popular se articula siempre en el mercado (Quijano, 2011:380). Agrega que las relaciones recíprocas y el mercado no se contraponen; sin embargo señala que están más presentes las reglas del mercado y del salario, ya que la reciprocidad opera desde afuera de las relaciones de trabajo. En este caso, la lógica de mercado condiciona y pone límites a la lógica de reciprocidad. 


\section{Sobre la autogestión del territorio}

La autogestión del territorio implica, de manera general, la forma cómo la agrupación decide organizar su espacio. La junta directiva, es la única entidad encargada de gestionar los lotes pertenecientes a la agrupación.

Habitantes de ambas agrupaciones nos han detallado un mismo proceso de admisión. Aquel interesado en adquirir un lote debe mandar una solicitud a la junta directiva, esta analizará la propuesta ante la asamblea, quien dispone si se admite el ingreso o no. Usualmente, el pago para ingresar a la agrupación varía de acuerdo al estatuto. Pero definitivamente resaltamos que el precio de un lote ahora es casi diez veces el precio con el cual los primeros habitantes lo adquirieron.

Otro punto en común en ambas agrupaciones, es la importancia que ambas le dan al hecho de que el nuevo propietario realmente viva en su lote. Para la junta directiva es una prioridad vender un lote para alguien que realmente lo necesite, para alguien que precise urgentemente de un lugar para vivir.

Ese es el caso de Yanira de Nueva Generación, que explica su situación actual:

Acá yo he tenido apoyo bastante. He tenido apoyo porque sí en realidad yo necesito. Yo he necesitado y es por eso también que me ven acá y me lo dicen, ¿no? Como vez hay un montón de casas que de repente lo adquieren por tenerlo o por algún negocio, no lo sé. Pero en cambio, yo no, yo lo adquirí, a la semana me propuse venir a vivir.

Lo mismo ocurrió con Aida, quien en todo momento sintió presión de parte del dirigente para que ella se asiente en U6A:

Vinimos a ver y había un espacio chiquito yo decía: "ya pues, qué importa vamos; si no nos acostumbramos nos volvemos". No me acostumbraba, yo me iba y me venía. Así estaba. De ahí el dirigente que se llamaba Chinder Tarazona, él me cuadró un día. Cuando me estoy yendo me dice "Vecina, vecina, acá no tenemos turistas, queremos vivencia, día y noche" Le contesté que venía a dormir todos los día. Me dijo: "Pero no, queremos de día también estés sentado en su casa, así tiene que ser, si no, desalojando porque necesitamos personas que vivan acá.

En Nueva Generación ocurre una situación muy particular en cuanto a la autogestión del territorio. La actual junta directiva está cotizando los lotes de acuerdo a una lógica de mercado, vendiendo los lotes por encima de los precios acordados en su estatuto. Todo esto a espaldas de los habitantes. Elizabeth, detalla que:

Sí, todavía hay lotes vacíos. Se tiene que presentar una solicitud y eso lo vemos en las asambleas. En la parte alta están los terrenos en venta, si estos están al lado de la carretera que tenemos proyectada, cuestan 2000 soles, si es más alejado, 500 soles. Esta carretera tenemos que construirla nosotros mismos, y los que más se involucran son los nuevos, los que viven arriba; los antiguos tienen menor participación.

La cotización de estos lotes vacíos ejemplifica la idea de Quijano (2011) sobre la hegemonía de la lógica de mercado sobre la lógica de reciprocidad. Se supone que los lotes deben ser vendidos a quienes precisan de un hogar, pero resulta obvio que una persona con escasos recursos nunca va a poder conseguir 2,000 soles por un lote que no cuenta con agua ni con luz. Al fijar este precio, la junta demuestra deseos de lucrar con su venta y evidencia la imposición de la lógica de mercado.

\section{c. Conflictos internos}

\section{Formas de coerción en las faenas}

Un problema transversal a ambas juntas directivas es el desinterés que perciben de sus representados con respecto a la organización política. Este desinterés se percibe por sobretodo en la ausencia de buena parte de los habitantes en las asambleas y en las jornadas de faena. Ambas agrupaciones están tomando medidas para frenar estas actitudes.

En U6A, por ejemplo, la tesorera de la junta, Aida del Valle nos comenta:

En las faenas también, el que quiere baja, el que puede bajar. Ahora hemos dicho que el que no baja paga 50 soles. ¡Y no bajan! Es que no hay con qué... Ahorita yo estoy pensando hacer una tarjeta de cada morador y cada faena hacer sellar como en el colegio. Ojalá que funcione, porque ayer estaba piensa y piensa porque íbamos a hacer esto y nadie viene.

Sucede algo similar en Nueva Generación, la secretaria de la junta, Elizabeth, nos cuenta:

Aquí se llama a Asamblea y si no bajan hay una pena. No, nosotros no cobramos, nosotros contamos las faltas y si sobrepasan el máximo decidimos quitar- 
los del padrón. De esa forma no tendrán derecho a empadronarse si acumulan faltas. Eso hacemos nosotros, sino no bajan.

No tenemos ninguna duda que las juntas directivas deben tener la disposición de trabajar, así como también, las juntas deben contar con el apoyo incondicional de los habitantes que representan. Es aquí, donde se percibe una marcada contradicción. Los habitantes de U6A y Nueva Generación desean que sus respectivas agrupaciones cuenten con muros, losas deportivas, escaleras y pilones; pero poco es el esfuerzo que están dispuesto a realizar para conseguirlos.

\section{Razones del desinterés hacia los fines de la agrupación}

Hemos logrado recoger dos razones totalmente distintas que explican el actual desinterés de los habitantes por participar. La primera razón, ya conocida, según la literatura producida sobre los movimientos de pobladores urbanos, es que con la obtención de los servicios básicos y del título de propiedad, la unión entre los habitantes se resquebraja debido a que ya no hay horizontes comunes.

En U6A, Aida critica:

"¿Qué ha empeorado? La desunión. Desde la fecha que hemos conseguido títulos de propiedad-la mitad somos titulados- de esa fecha que entregó título de propiedad, llamaba faena, nadie bajaba, llamaba asamblea, nadie bajaba.

La segunda razón, es la poca confianza que existe entre la junta directiva y los habitantes. Esta razón se plasma dramáticamente en Nueva Generación. En donde existe un amplio consenso de que los dirigentes de todas las juntas directivas que han pasado, han sido poco honestos y éticos:

Ahorita la gente está desunida porque el dirigente se te acerca y te dice: "No, ¿̇abes qué? tú tienes que pagar esto y esto de la cuota, porque en la municipalidad dicen tal cosa porque hace falta tal cosa y el abogado dice que también se pague esta otra cantidad porque se necesita esto otro". Entonces, nos engaña como se dice, ¿¿no? Porque no ha pasado lo que ellos han prometido, han pasado ańos de ańos y se sigue en lo mismo. Entonces la gente de acá ya no quiere hacer nada.
En Nueva Generación además, resalta que los habitantes consideran que su junta directiva direcciona mal las faenas. Juzgan a su junta como poco realista y poco ética. José señala:

Hay reuniones, pero la verdad es que yo soy una persona práctica y no me gusta gastar saliva, porque a veces se discuten temas imposibles pues. Por ejemplo quieren poner un pilón, y se necesita cosas, y lo quieren poner arriba en la punta del cerro y defensa civil ha dicho que eso estaría en zona de riesgo, pero los dirigentes siguen insistiendo, dicen que por debajo o rompiendo la mano.

La percepción que tienen los habitantes de Nueva Generación sobre su junta es en general muy mala. En comparación, los habitantes de U6A rescatan que todos sus dirigentes siempre han sido personas trabajadoras, honestas y limpias. Es pertinente preguntarse si esta continua desconfianza de Nueva Generación, en sus dirigentes, socavará su organización interna y las posibilidades de seguir desenvolviendo faenas comunitarias.

\section{Relaciones con agentes de su entorno}

Este apartado tiene como objetivo indagar en torno a los agentes que están relacionados directa e indirectamente con las AF investigadas. Así también busca dilucidar el uso de las vinculaciones políticas de ambas agrupaciones. Por razones de espacio centra la atención en dos de las más determinantes:

\section{a. Unión de Pueblos Organizados}

La Unión de Pueblos Organizados (en adelante UPO) es una organización con connotaciones políticas, su objetivo es agrupar a las juntas directivas de las zonas altas de JCM.

Dicha organización es creada durante el 2012, con el propósito de reunir a unas pocas AF para que sean acreedoras de la ayuda de un líder social. Dicho "líder social” era el señor Juan Navarro, el cual aún no poseía el cargo de alcalde de la Municipalidad de San Juan de Lurigancho. La UPO contaba inicialmente con AF como Cerro Celeste, San Pablo, Huáscar, etc. Dichas agrupaciones recibían distintos tipos de ayuda o donaciones; las cuales iban desde alimentos como cuartos de pollos hasta materiales de construcción como bolsas de 
cemento. Con el fin, según su benefactor, de "ayudar a los pueblos olvidados de San Juan de Lurigancho".

La ayuda que Navarro impartía, se utilizaba para organizar polladas comunitarias o aguaditos, ambos con el fin de conseguir fondos para la construcción de escaleras y lozas deportivas.

Hace tres semanas hemos realizado la donación de cuartos de pollo, primer comenzamos con San Fernando unos 320 cuartos pollo y de ahí hemos donado también 360 de pollo y también hemos donado 400 cuartos de pollo para Cerro Celeste también estamos inaugurando los Aguaditos con Juan Navarro, de aquí en adelante diferentes pueblos se van a ver beneficiados. $^{2}$

Sin embargo, todos estos tipos de donaciones necesitaban ser "pagadas" a su benefactor de alguna manera. La modalidad de pago utilizada por las AF fue con votos hacia la campaña que se gestaría en los años siguientes y que llevaría a la alcaldía a Navarro.

La señora Teófila de la AF U6A nos comentó ello:

(...) Navarro siquiera nos ha donado en pollo, y por eso esta escalera que hemos hecho acá abajo hemos acabado con el pollo nos ha apoyado (...). Ya apareció como candidato y le tuvimos que apoyar. Lo hemos apoyado en mítines, pero ahora ya no.

Con Navarro como alcalde se consolidó dicha agrupación, en la actualidad cuenta con la integración de más de 60 AF, entre ellas la agrupación "U6A".La UPO a su vez figura como un "agente participativo" de la comuna 17 en el presupuesto participativo de San Juan de Lurigancho y se encuentra bajo la dirección del señor Rufino Condori Luque; este último no solo es el cofundador de dicha agrupación sino también el nexo con la municipalidad. La dirigente Rosalinda de la AF "Rocas de Bellavista" menciona al respecto:

Nosotros nos reunimos los días jueves, como Unión de pueblos. Tenemos reunión con todos los dirigentes (Cerro Celeste, San Pablo, etc.) [ ] todos tenemos la misma necesidad, por eso todos estamos unidos ahí, nuestras peticiones luego las escucha el alcalde, sacamos audiencia un día antes y hablamos cara a cara.

2 Declaraciones de Juan Navarro (Actual alcalde) en el video "El aguadito con Juan Navarro" 17/06/2012 [https:/www.youtube.com/ watch? $=$ s $4 \mathrm{iCN}$ rfN1-U]
La gran mayoría de estas AF inscritas en esta organización han recibido una "ayuda" por parte de la actual gestión, a la cual se refieren de una manera muy positiva e incluso ellos creen que son parte de una suerte de "democracia participativa". En la actualidad U6A construye un muro de contención, en gran medida, gracias al apoyo de esta agrupación.

Por su parte, el actual alcalde tiene presente la importancia de esta organización, ya que periódicamente se reúne con ellos por medio de audiencias, en donde escucha sus demandas. Sin embargo, sólo son escuchadas y atendidas las peticiones de aquellos pertenecientes a dicha organización, ya que agrupaciones como "Portadas de Belén" y "Nueva Generación" son seriamente obstaculizadas en los tramites documentarios y se les cierran puertas. Los demás miembros de la agrupación mencionan que se debería al no apoyo de estas agrupaciones en la campańa electoral del alcalde Navarro.

El señor Santa Cruz, dirigente de Nueva Generación nos mencionaba:

Nosotros estamos en busca de planos, tenemos ya un proyecto para la construcción de la loza y un muro, pero cuando vamos a la municipalidad o voy al ministerio me dicen, que aquí no es, que es allá, que regrese en dos semanas, te dan vueltas pues.

Sin embargo, la señora Rosalinda, dirigente de Rocas de Bellavista, afirma:

Ellos (Nueva Generación y Portadas de Belén) no quieren entrar a la "unión", ellos quieren que les den a ellos solos, además ellos apoyaban a otro candidato, ellos tienen que acercarse a nosotros.

Este tipo de relaciones que se tejen a partir de una vinculación política, han sido utilizadas por dichas agrupaciones como una herramienta eficaz para la obtención de beneficios en sus agrupaciones, sin embargo, también salta a la vista el tipo de relación clientelar, entendiendo este término como:

La consecuencia de una relación personal de intercambio, en el ámbito de la política, que se establece de forma voluntaria y legítima, dentro de la legalidad, entre los que pueden ocupar u ocupan cualquier cargo público y los que desean acceder a unos servicios o recursos públicos a los que es más difícil llegar, que no imposible, de no ser por este vínculo o relación. (Coro Fernández, 2002: 14). 
Los miembros de esta organización han normalizado este tipo de relación clientelar con el actual alcalde aludiendo principalmente a todos los beneficios que han obtenido.

Es así como se gesta un caso atípico de red de reciprocidad que contempla sus bases en el clientelaje político, con el fin de beneficiar la subsistencia de dichas agrupaciones familiares; pero donde puede deducirse a su vez que constituye una estrategia a la cual apelan para cubrir necesidades.

\section{b. Instituto de Desarrollo Urbano Cenca}

El Instituto de Desarrollo Urbano Cenca es un organismo no gubernamental especializado en planificación y mejoramiento del hábitat, apoyo a la promoción de iniciativas económico sociales sostenibles; por medio del desarrollo de capacidades y actitudes de sus habitantes.

Este Instituto lleva incidiendo varios años en las agrupaciones de JCM, con el fin de brindar apoyo legal y técnico a estas. Para ello, cuenta con distintos proyectos de incidencia dentro de las AF, las principales se centran en el mejoramiento de viviendas, habilitación de las mismas y fortalecimiento de las organizaciones vecinales.

Cenca ha influido en la consolidación de relaciones entre las agrupaciones, a partir del fomento de diversos talleres y actividades de capacitación, las y los participantes de estas actividades tienen la posibilidad de conocer a los demás vecinos de las distintas agrupaciones encontrándose muchas veces con experiencias parecidas y las mismas necesidades. Cenca además, bajo la línea de "fortalecer" vínculos, fomenta una serie de actividades recreativas y deportivas, como campeonatos de futbolito y voleibol.

Sin embargo, más allá del rol de promoción que cumple esta organización, los miembros de ambas AF ven a esta institución como una "nueva esperanza", atribuyéndole en muchos casos funciones que no puede cumplir. Incluso confunden las labores de este organismo, con las funciones que debería cumplir el Estado y la municipalidad.

Es necesario anotar que Cenca desenvuelve una labor asistencialista. Esto debido a que los proyectos que maneja en la zona, no brindan las herramientas suficientes en pro de un desarrollo autónomo de estas agrupaciones.
La mejora de viviendas y la donación de casas pre fabricadas a las personas "más necesitadas", por ejemplo, responde a un discurso centrado en la idea de "salvar a los pobres". Dentro de estas medidas "humanitarias" de apoyo no se logra hacer clara la idea de un despliegue de capacidades desde los propios AF. Su ayuda queda reducida a resolver problemas materiales inmediatos, de corto plazo, más no a la creación un desarrollo autónomo de dichas agrupaciones.

Es necesario mencionar la importancia de los talleres para el "desarrollo de capacidades", pero este desarrollo de capacidades tiene la limitación de centrarse únicamente en los aspectos social y jurídico, sin considerar el aspecto económico. Entendemos que el desarrollo no debe estar ligado solo al aspecto económico, y se debe trabajar lo social y lo jurídico también; sin embargo, no se registra en su labor una intervención que incluya lo económico.

Nos preguntamos qué tipo de escenario espera a estas agrupaciones cuando este organismo deje de brindar su ayuda, cuando no posee el financiamiento para sostenerla o cuando la institución cumpla sus propias metas. ¿Estas agrupaciones podrán seguir desenvolviendo las actividades de desarrollo de capacidades?

\section{Perspectivas a futuro}

La perspectiva de desarrollo de ambas AF, está vinculada con dinámicas que implican "estrategias de sobrevivencia” como lo menciona Quijano. La fuerza de trabajo de la que hacen uso, no está orientada a una remuneración monetaria sino más bien buscan el beneficio social comunitario.

El ejemplo de ello es la construcción de un muro de contención. Las agrupaciones familiares mencionadas dan su fuerza de trabajo para continuar esa obra cuya finalidad es evitar los posibles derrumbes y o deslizamientos causados a causa de las lluvias. Dichas acciones de forma colectiva reciben la denominación, por parte de las personas allí residente, de "faenas comunales". Ésta es una perspectiva a futuro que la tienen muy presente: apoyar e involucrarse.

La reciprocidad, siguiendo a Quijano, se asocia a la idea de intercambio de fuerza de trabajo y de trabajo (productos, tangibles e intangibles), sin la intermediación del mercado (2011: 376). En este sentido, las faenas comunales que realizan las personas para terminar de construir un muro de contención se asocian a las 
dinámicas internas que no apuntan a recibir un salario sino más bien a generar un beneficio social-simbólicocomunitario que recae en la misma agrupación social.

Los dirigentes poseen un respaldo medianamente aceptable de la población para consensuar propuestas; pero, reciben la traba de papeles, de burocracia y de dinero por parte de su municipalidad.

Asumir liderazgos horizontales, que respondan a los intereses de U6A es importante para generar confianza y consolidar propuestas que merezcan una especial atención. Por ejemplo, la idea de obtener medidores de luz individuales así como el tener títulos de propiedad son consignas que vendrían a significar su desarrollo en un segundo nivel. Asumimos que el primer nivel de necesidades está asociado a la ocupación del lugar, obtener los servicios básicos, por medio de los vecinos, y construir casas pre fabricadas.

En ese sentido, la perspectiva a futuro que podemos identificar es que la participación política permanecerá por las demandas sociales; pero se hace necesaria una renovación de cuadros y liderazgos de tipo horizontal para fortalecer lazos sociales y de confianza.

Entonces, es necesario reforzar los lazos de solidaridad y reciprocidad entre la comunidad y los actores institucionales para que se involucren y sostengan esta manifestación de economía popular con una orientación al grupo, a lo social.

\section{Conclusiones}

¿Economía popular de la ciudad? Esta pregunta se puede responder mejor si decimos que la periferia de la ciudad de Lima genera hoy una economía popular. Ahí, como hemos visto en U6A y Nueva Generación, existen condiciones materiales que obligan a la gente a unirse y aunque su unión sea la consecuencia de esas condiciones se puede ver que en mayor o menor medida sus lazos de solidaridad y reciprocidad persisten como en el caso notorio de U6A.

Entonces, podemos decir, aunque las condiciones son similares de ambos casos y los han obligado a crear actividades de autogestión y autogobierno (faenas comunales, locales comunales, juntas directivas, etc.), que existen factores que hacen que en U6A esto sea más notorio y que los lazos de solidaridad y reciproci- dad no se hayan resquebrajado en el mismo grado que en Nueva Generación.

Un factor importante es la "vinculación política" actual que han establecido con la UPO. Si bien esta vinculación reproduce relaciones de clientelaje político esto pasa a un plano secundario para las $\mathrm{AF}$, porque sus integrantes ven en la relación con esta organización una oportunidad de obtener recursos y el apoyo que les era negado, en anteriores épocas, por parte de las varias gestiones municipales, tanto de Lima como de San Juan de Luirgancho.

Otro elemento es la confianza que se tiene en la junta directiva de las AF. Esta confianza se ve resquebrajada por diversos motivos como ya hemos visto: los escasos logros obtenidos durante una gestión, los abusos cometidos por parte de algunos dirigentes, el dinero perdido, son algunas de las causas que determinan el debilitamiento de la confianza. Por otro lado, esta confianza se refuerza cuando se ve que "la junta directiva está trabajando", es decir, genera ciertas mejoras para su agrupación familiar.

Entonces, podemos decir que a pesar de las adversidades a las que se tienen que enfrentar las distintas AF, en las partes altas del asentamiento humano JCM, estas terminan expresando de manera distinta los mecanismos para contrarrestar estas adversidades. Aunque estos mecanismos, nos atreveríamos a decir, se encuentran dentro de la "economía popular" pueden verse trastocadas según la situación particular de cada agrupación familiar y las estrategias específicas que desenvuelvan.

Así, el futuro de estas AF es incierto sin apoyo externo, pareciera que los lazos de solidaridad no bastan, es decir, la economía popular resulta ineficiente para superar las dificultades que se presentan por vivir en esta zona; sin embargo, descartamos que el mercado o el Estado tenga la capacidad, guiándonos de su situación actual, para poder brindar apoyo a las AF de las partes altas del asentamiento humano JCM.

Por lo tanto, si no confiamos en que la gente, y su ingenio, busque la forma de seguir con un proceso de trabajo comunitario propenso a tender relaciones fundadas en un racionalidad basada en la solidaridad y la reciprocidad, les será imposible poder superar las dificultades agudas que hoy enfrentan y avisorar un futuro para ellas y sus familias. 


\section{Bibliografía}

Arocena, J. (2002). El desarrollo local: Un desafío contemporáneo, Montevideo: Editorial Taurus.

Cabrera, C. y Vio, M. (2014). Las tramas sociales de la economia popular, Buenos Aires: Espacio Editorial.

Coraggio, J. (2016). "La economía social y solidaria (ESS): niveles y alcances de acción de sus actores. El papel de las universidades", en; Carlos Puig (Coordinador) Economía social y solidaria: conceptos, prácticas políticas públicas. Bilbao: Hegoa Instituto de Estudios sobre Desarrollo y Cooperación Internacional del País Vasco.

Coraggio, J. (2011). "La Economía Social como vía para otro desarrollo social”, en: Acosta, A. y Martínez, E. (Editores). Jose Luis Coraggio Economía Social y Solidaria. El trabajo antes que el capital, Quito: Ediciones Abya- Yala.

Corzo Fernández, S. (2002). "El clientelismo político como intercambio", Institut de Ciències Polítiques i Socials, 14.

Estrada, C. E. (2015). "La gestión del territorio en Jose carlos Mariategui”, en: Cuadernos Urbanos, 30-37.

GermanÁ, César (2016). "La economía de la reciprocidad y el buen vivir", en: Hanne Cottyn, Javier Jahncke, Luis Montoya, Ela Pérez, Mattes Tempelmann (Editores), Las luchas sociales por la tierra en América Latina. Un análisis histórico, comparativo y global. Lima: Seminario de Economía Social, Solidaria y Popular. Facultad de Ciencias Sociales, UNMSM.
Marañón Pimentel, Boris (2016). "Notas sobre la solidaridad económica y la descolonialidad del poder", en: Boris Marañón Pimentel (Coordinador), Políticas para la solidaridad económica y el buen vivir en México. Ciudad de México: Instituto de Investigaciones Económicas de la Universidad Nacional Autónoma de México.

Muñoz, R. (2011). "Análisis y desafíos de la economía popular urbana. Reflexiones a partir de análisis sectoriales y casos de estudios de la Región metropolitana de Buenos Aires", en: Urquieta, P. (Coordinadora). Ciudades en transformación. Disputas por el espacio, apropiación de la ciudad y prácticas de ciudadanía, La Paz: CIDES Universidad Mayor de San Andrés.

Quijano, A. (2011). "Sistemas alternativos de producción?”, en: Santos, B. (Coordinador). Producir para vivir. Los caminos de la producción no capitalista, México D. F.: Fondo de Cultura Económica.

Quispe, J. (2015). "Breve análisis de la ejecución del Plan Nacional de vivienda 2006-2015", "Vivienda para todos", Cuadernos Urbanos, 21-30.

Riofrío, G. (2009). "Imágenes y perspectivas del crecimiento urbano en Lima”, en: Bedoya S. Los nuevos rostros de la ciudad de Lima, Lima: Colegios de Sociologos del Perú.

Santos, B. (2011). "Introducción. Para ampliar el canon de la producción”, en: Santos, B. (Coordinador). Producir para vivir. Los caminos de la producción no capitalista, México D. F.: Fondo de Cultura Económica. 